\title{
MENGITEGRASIKAN TRADISI-TRADISI DALAM SOCIAL STUDIES DAN STRATEGI PENDIDIKAN NILAI KOMPREHENSIF DALAM RANGKA MEMECAHKAN MASALAH SOSIAL
}

\author{
Suyato \\ Jurusan PKN dan Hukum Universitas Negeri Yogyakarta
}

\begin{abstract}
Abstrak
Krisis nilai dan moral yang melanda Indonesia dewasa ini bisa dijadikan indikasi kegagalan pendidikan nilai dan moral baik di sekolah, keluarga, maupun masyarakat. Social studies yang merupakan salah satu mata pelajaran yang memiliki misi pendidikan nilai dan moral selama ini cenderung menggunakan atau menekankan secara lebih berat pada satu tradisi dan strategi pembelajaran tertentu sehingga lebih bersifat parsial.

Mengingat permasalah nilai dan moral yang demikian berat melanda negara ini, para guru Social Studies perlu melakukan perubahan, khususnya pemilihan strategi pembelajaran yang selama ini terbutli kurang efektif. Salah satu cara itu adalah dengan mengintegrasikan tradisi dan strategi pembelajaran. Dengan mengintegrasikan tradisi social studies sebagai pendidikan kewarganegaraan, ilmu sosial, reflective inquiry dan mengintegrasikan strategi pendidikan nilai baik inkulkasi, fasilitasi, pemodelan, maupun pengembangan ketrampilan berkaitan dengan nilai, termasuk pendidikan nilai komprehensif baik materi, media, pelaku, waktu, tempat dan evaluasi diharapkan pendidikan nilai akan lebih efektif. Dengan pendidikan nilai dan moral yang efektif diharapkan akan tercipta warga negara yang memiliki integritas nilai dan moral yang tangguh sehingga krisis nilai dan moral yang melanda negeri ini segera teratasi.

Meskipun guru telah melakukan tugasnya dengan baik, tanpa dukungan dari orangtua, tokoh masyarakat, dan pemerintah, pendidikan nilai tidak akan efektif. Oleh karena itu, pendidikan nilai dan moral yang komprehensif menuntut kerjasana semua stake holder untuk bahu-membahu secara sinergis dan berkesinambungan dalam upaya mendidik anak bangsa menjadi insan yang memiliki integritas nilai dan moral yang tangguh.
\end{abstract}

Kata-kata kunci: social studies, pendidikan nilai, komprehensif.

\section{A. Pendahuluan}

Krisis nilai dan moral yang melanda Indonesia dewasa ini telah begitu memprihatinkan, khususnya bagi mereka yang peduli akan nasib generasi mendatang. Jalur yang paling tepat untuk mengatasi masalah ini adalah sekolah. Mengutip pendapat Hill (1991: 166), sekolah bisa berfungsi sebagai 'titik 
penghubung' atau a liaison point. Masing-masing dari tiga lingkungan pendidikan, sekolah, keluarga, dan masyarakat-, memiliki kelebihan dan kelemahan. Oleh karena itu, satu sama lain saling membutuhkan. Kerja sama dan saling menghormati perlu ditunjukkan sekolah kepada dua lingkungan lainnya. Jadi, guru, misalnya, jika memandang perlunya menumbuhkan kepekaan terhadap masalah nilai dan pelatihan pendidikan nilai bagi para orang tua dan tokoh masyarakat, maka perlu kiranya menghargai saran dan pendapat mereka. Sikap dan kesan menggurui dari pihak sekolah perlu dihindari. Kerjasama dalam suasana saling menghargai dan saling membutuhkan perlu diciptakan.

Keyakinan siswa dan orang tua bahwa dirinya mampu, merasa sebagai bagian, dan ikut memberikan kontribusi, atau dalam istilah Albert (1989: 9), three Cscapable, connect, contribute, adalah tiga kunci keberhasilan penanaman disiplin kooperatif. Makalah ini mengusulkan sebuah gagasan pengembangan program pendidikan nilai di sekolah yang bersifat komprehensif dengan melibatkan tiga pusat pendidikan dengan memperhatikan tiga prinsip dari Albert ini.

Permasalahan sosial yang semakin pelik biasanya dikaitkan dengan social studies. Para guru dan pakar tentang disiplin ilmu ini dianggap bertanggung jawab terhadap masalah itu. Singkatnya, permasalah sosial muncul sebagai pertanda gagalnya para pendidik khususnya para guru social studies. Mereka dianggap telah gagal menyiapkan anak didiknya untuk menjadi warga negara yang baik (good citizen). Masalah ini bertambah rumit karena yang dimaksud masalah sosial juga masih sangat kabur. Untuk itu, perlu diklarifikasi terlebih dahulu apa yang dimaksud dengan masalah sosial itu. 
Definisi tentang masalah sosial sangat beragam. Bila anda bertanya kepada 20 orang definisi tentang masalah sosial, anda akan mendapatkan 20 jawaban yang berbeda. Namun demikian, para sosiolog sepakat bahwa sebuah masalah minimal harus memenuhi tiga syarat untuk dapat dikategorikan sebagai masalah sosial, yaitu: (1) berasal dari sosial atau struktural; (2) masalah itu cukup besar; dan (3) masyarakat mampu menanganinya (McDowell, 1986:4). Oleh karena itu, sebuah masalah bisa menjadi masalah sosial tergantung pada persepsi atau anggapan masyarakat. Bisa jadi, suatu masalah pada saat tertentu bukan merupakan masalah sosial yang serius, pada saat yang lain merupakan masalah sosial yang sangat serius.

Sebagaimana kita ketahui, para pendidik dan pakar social studies telah lama melakukan perdebatan tentang hakikat disiplin ilmu ini. Dari waktu ke waktu istilah social studies semakin populer. Bahkan menurut Atwood (Martorella, 1994: 5) menyatakan bahwa era tahun 1980-an merupakan era masa kedewasaan disiplin ilmu ini. Selengkapnya ia menyatakan sebagai beikut:

It can be argued that the 1980's must be the adolescent period for social studies as social studies educators, through their journals and in dialogue at national and regional meetings, are diligently seeking consensus on definition and purpose, as well as agreement on scope and sequence. At this point it is unclear how long the adolescent period will last for social studies.

Namun demikian, sampai saat ini bila kita simak secara seksama ternyata belum ada kesepakatan tentang definisi dari disiplin ilmu ini. Berikut ini adalah beberapa definisi tentang social studies:

The social studies are the social sciences simplified for pedagogical purposes (Wesley, 1950: 34).

Social studies is the integrated study of the social sciences and humanities to promote civic competence (NCSS, 1993: 3). 
The social studies are concerned exclusively with the education of citizens. In a democracy, citizenship education consiss of teo related but somewhat disparate parts: the first socialization, the second countersocialization (Engle \& Ochoa, 1988: 13).

The social studies is an integration of experience and knowledge concerning human relations for the purpose of citizenship education (Barr et al., 1977: 69).

\section{B. Tradisi-Tradisi dalam Social Studies}

Barr (Chapin \& Messick, 1992: 7) meringkas ada tiga tradisi utama social studies sebagai berikut:

Social Studies Taught as Citizenship Transmission

Purpose-Citizenship is best promoted by inculcating right values a framework for making decisions.

Method-Transmission: Transmission of concepts and values by such techniques as textbook, recitation, lecture, question and answer sessions, and structured problem-solving exercises.

Content-Content is selected by an authority interpreted by the teacher and has the function of illustrating values, beliefs, and attitudes.

Social Studies Taught as Social Science

Purpose-Citizenship is best promoted by decision making based on mastery of social science concepts, processes, and problems.

Method-Discovery: each of the social sciences has its own method of gathering and verifying knowledge. Student must discover and apply the method that is appropriate to each social science.

Content-Proper content is the structure, concepts, problems, and processes of both the separate and the integrated social science disciplines.

Social Studies Taught as Reflective Inquiry

Purpose-Citizenship is best promoted through a process of inquiry in which knowledge is derived from what citizens need to know to make decisions and solve problem.

Method-Reflective Inquiry: Decision making is structured and disciplined through a reflective inquiry process which aims at identifying problems and responding to conflicts by means of testing insights.

Content-Analysis of individual citizen's values yields needs and interests. These, in turn, form the basis for student self-selection of problems which constitute the content for reflection. 
Di samping tiga tradisi tersebut, Chapin \& Messick (1992: 10-11) menambahkan dua tradisi lagi dalam Social Studies. Pertama, tradisi yang menyarankan bahwa tujuan social studies dan juga disiplin ilmu lainnya seharusnya berpusat pada siswa dan diarahkan secara langsung pada pengembangan pribadi. Fokusnya adalah pada pengembangan potensi anak yang bersifat unik dengan cara memberi kesempatan berkembangnya kreativitas, integritas pribadi, cinta akan belajar, dan mandiri. Para siswa seyogyanya merasa bahwa mereka mampu atau kompeten membuat keputusan atau pilihan dan bahwa mereka dapat mempengaruhi diri sendiri dan orang lain. Pendekatan yang berpusat pada siswa ini, yang lebih memusatkan pada pemenuhan kebutuhan individu daripada kebutuhan masyarakat, mendorong siswa untuk mencapai sebuah pemahaman tentang kebutuhan mereka sendiri dan untuk bekerja dengan orang lain untuk mencapai tujuan-tujuan mereka. Pendekatan ini kadang-kadang diikuti oleh para guru dengan menggunakan filsafat Montessori.

Kedua, tradisi yang bisa disebut social studies sebagai informed social criticism, atau new criticism. Pendekatan ini, yang didasarkan pada Marxisme, menuntut agar siswa diberi kesempatan untuk menganlisis secara kritis dasar ideologi yang melandasi sekolah dan masyarakat mereka. Barangkali kita susah untuk menemukan pendekatan ini dalam praktik persekolah, khususnya di tingkat dasar dan menengah, tetapi merupakan hal yang biasa dalam perguruan tinggi, khususnya dalam wacana social studies.

Dari kelima tradisi ini, mana yang paling dekat dengan praktik persekolahan? Untuk menjawab pertanyaan ini memang susah karena para guru biasanya 
menggabungkan ketiga tradisi utama. Mereka memilih dari beragam pendapat tergantung materi yang sedang diajarkan. Mereka kadang-kadang cenderung bersifat indoktrinasi, khususnya ketika mengajarkan nilai-nilai dan patriotisme pada kelas rendah, sambil juga mendorong siswa untuk memikirkan isu-isu tentang kebijakan sosial. Mereka pada suatu saat mengajarkan satu unit tentang masalah dalam masyarakat dengan menggunakan pendekatan inquiry, pada saat lainnya mengajarkan tentang pemerintahan lokal dengan menggunakan pendekatan transmisi kewarganegaraan secara tradisional. Barangkali yang jarang dilakukan oleh guru pada pendidikan dasar adalah tradisi social studies yang diajarkan sebagai ilmu sosial. Pendekatan ini agak susah diimplementasikan kecuali guru bersedia untuk melakukan persiapan yang luar biasa, khususnya berkaitan dengan materi karena biasanya bukubuku teks social studies untuk kelas rendah merupakan gabungan dari berbagai displin ilmu sosial.

Dari pemaparan di muka dapat disimpulkan bahwa definisi, isi, dan tujuan social studies sangat beragam tergantung sistem nilai dan orientasi filosofis dari para guru dan pengembang kurikulum. Pendekatan kewarganegaraan atau transmisi nilainilai sejarah cenderung untuk menekankan nilai, sejarah, dan prestasi bangsa untuk meningkatkan jiwa dan semangat nasionalisme siswa. Pendekatan ilmu sosial menggunakan isi dari beragam disiplin ilmu sosial dan sejarah dengan pandangan untuk memahami konsep-konsep utama dan metode pengupulan data. Sedangkan pendekatan atau tradisi reflective inquiry dapat menggunakan hampir seluruh materi sejauh ia mampu mendorong kemampuan berpikir kritis dan reflektif. 


\section{Pendidikan Nilai yang Komprehensif}

Yang dimaksud dengan pendidikan nilai yang komprehensif di sini adalah komprehensif dalam hal isi, metode, waktu, pelaku, dan evaluasi. Komprehensif dalam hal isi mencakup realisasi nilai, pendidikan karakter, pendidikan kewarganegaraan, dan pendidikan moral (Kirschenbaum, 1995:16-17).

Komprehensif dalam isi, dapat dikemukakan dalam tabel berikut ini:

\begin{tabular}{|c|c|c|}
\hline No. & Aspect & Contents \\
\hline 1. & Values Realization & $\begin{array}{l}\text { Knowing Oneself-one's feelings, beliefs, priorities. } \\
\text { Self-Esteem } \\
\text { Gola-Setting Ability } \\
\text { Thinking Skills—critical thinking, creative thinking } \\
\text { Decision-Making Skilla. } \\
\text { Communication Skills. } \\
\text { Social Skills. } \\
\text { Knowledge of the World. }\end{array}$ \\
\hline 2. & Character Education & $\begin{array}{l}\text { Respect-for others, for oneself, for property, for } \\
\quad \text { environment. } \\
\text { Resposibility—reliable, honest, trustworthy } \\
\text { Compassion—kind, helpful, friendly, empathic, humane, } \\
\quad \text { tolerant. } \\
\text { Self-Diciplin-perseverance, thrift } \\
\text { Loyalty } \\
\text { Courage } \\
\text { Work Ethic, etc. }\end{array}$ \\
\hline 3. & $\begin{array}{l}\text { Citizenship } \\
\text { Education }\end{array}$ & $\begin{array}{l}\text { Knowledge-understanding history, democratic system. } \\
\text { Appreciation-heritage, rights and responsibilities, } \\
\quad \text { cultural diversity. } \\
\text { Critical Thinking Skills. } \\
\text { Communication Skills. } \\
\text { Cooperation Skills. } \\
\text { Conflict Resolution Skills. }\end{array}$ \\
\hline 4. & Moral Education & $\begin{array}{l}\text { Moral Knowledge-understanding moral tradition, } \\
\text { justice, fairnes, ethics. } \\
\text { Moral Reasoning-higher level reasoning, reversing } \\
\quad \text { roles, examining consequences, etc. } \\
\text { Compassion and Altruism. } \\
\text { Moral Tendencies-conscience, loving the good, self- } \\
\quad \text { control, humility, moral habit. }\end{array}$ \\
\hline
\end{tabular}


Komprehensif dalam arti metode atau cara meliputi inkulkasi, pemodelan, fasilitasi, dan pengembangan ketrampilan nilai dan moral (Kirscenbaum, 1995:31). Yang dimaksud dengan inkulkasi (inculcation) dalam The American Heritage Dictionary dinyatakan sebagai "to teach or impress by urging or frequent repetition; to instill”. Kirscenbaum (1995:33) membedakan inkulkasi dari indoktrinasi sebagai berikut:

\begin{tabular}{|l|l|}
\hline \multicolumn{1}{|c|}{ Inculcation } & \multicolumn{1}{|c|}{ Indoctrination } \\
\hline $\begin{array}{l}\text { Communicate what you believe and the } \\
\text { reason why you believe it. }\end{array}$ & $\begin{array}{c}\text { Communicate what you believe solely on } \\
\text { the basis of authority. } \\
\text { Treat other views fairly. }\end{array}$ \\
Accord respect to those with other views. & $\begin{array}{l}\text { Vilify, dehumanize those with other views. } \\
\text { Answer doubt with reason and respect. }\end{array}$ \\
Partially structure the environment to & Totally control the environment to increase \\
increase likelihood of exposure to & likelihood of exposure to desired \\
desired values and decrease likelihood & values and decrease likelihood of \\
of exposure to undesirable values. & exposure to undesirable values. \\
Create positive social, emotional, learning & Create positive social, emotional, learning \\
experiences around the desired & experiences around the desired \\
values-within limits. & values - to an extreme. \\
Provide rules, rewards and & Provide rules, rewards and \\
consequences-within reason. & consequences-to the extreme. \\
If someone disagrees, keep open lines of & If someone disagrees, cut off \\
communication. & communication. \\
Allow a certain latitude for divergent & Allow no latitude for divergent behavior; if \\
behavior; if beyond acceptable level, & beyond acceptable level, ostracize \\
leave open possibility of change. & totally and/or permanently. \\
\hline
\end{tabular}

Pemodelan (Modeling) merupakan hal yang umum, karena dua alasan. Pertama, guru memang seharusnya menjadi model dalam pendidikan nilai dan moral. Kedua, siswa seharusnya belajar dari model peran masa lalu. Dalam pemodelan ada beberapa hal yang kemungkinan terjadi, yaitu: (1) pemolaan (paterning); (2) untuk mendapatkan cinta dan persetujuan (to gain love and approval); (3) untuk menghindari rasa takut dan hukuman (to avoid fear and punishment); (4) untuk 
mencapai penghargaan lain (to gain other rewards); (5) asosiasi positif atau identifikasi (positive association; identification); dan (6) pemilihan sebuah alternatif secara sadar (consciously choosing an alternative ( Kirschenbaum, 1995: 34-35).

Fasilitasi memiliki sejumlah keunggulan sebagai berikut: (1) aktivitas fasilitasi dapat meningkatkan secara signifikan laporan anda berkaitan dengan siswa; (2) membantu semua siswa memperjelas pemikiran dan perasaan mereka tentang suatu masalah; (3) membantu siswa yang termasuk dalam kategori kedua, yaitu mereka yang menerima pemikiran tentang nilai tertentu tetapi bertindak secara tidak konsisten, untuk berubah dari pemahaman secara intelektual ke arah komitmen untuk bertindak; (4) membantu siswa yang termasuk dalam kategori ketiga, yaitu mereka yang belum memahami untuk berpikir lebih lanjut tentang materi atau nilai tertentu untuk memahami, belajar dari para siswa yang termasuk kategori pertama dan kedua, untuk akhirnya mengakui kebaikan yang guru ajarkan; (5) membantu siswa yang termasuk kategori terakhir, yang semula menolak untuk kembali bergabung; (6) membantu beberapa siswa yang skeptis, ysng semula bergabung tetapi tidak setuju dengan guru untuk menyuarakan keraguan, alasan ketidaksetujuan, atau masalah mereka; (7) membantu para guru memahami lebih dalam tentang bagaimana siswa berpikir dan merasakan; dan (8) aktivitas fasilitasi adalah aktivitas memotivasi yang membantu siswa menghubungkan antara isu nilai atau materi pelajaran yang sedang didiskusikan dengan kehidupan, keyakinan, dan perasaan mereka sendiri (Kirschenbaum, 1995: 41-42).

Komprehensif waktu, bahwa proses pendidikan nilai berlangsung di setiap saat sepanjang hidup anak. Komprehensif pelaku, bahwa program pendidikan nilai 
dapat (dan memang seharusnya) dilakukan oleh semua orang dewasa, sadar atau tidak, direncanakan atau tidak direncanakan. Sedangkan komprehensif dalam penilaian, maksudnya dalam mengukur efektivitas dan kemajuan perkembangan pendidikan nilai menggunakan evalusai formatif dan sumatif yang mengukur pengetahuan, sikap, dan ketrampilan nilai dan moral.

\section{Pengembangan Pendidikan Nilai Komprehensif: Inisiatif Sekolah}

Pengembangan program pendidikan nilai komprehensif di sekolah antara lain dapat dilakukan dengan cara:

a. kemitraan sekolah dengan keluarga. Kerjasama antara sekolah dan keluarga memang sangat perlu dan harus dilakukan. Kerjasama yang bersifat sinergis dan berkesinambungan disamping lebih efektif juga agar terjadi keselarasan antara nilai dan suasana yang dirasakan siswa di mana pun mereka berada, di sekolah, di rumah, maupun di masyarakat.

b. pengembangan suasana kelas yang positif yang memiliki karakterisrik, atara lain: saling memberi pengaruh yang positif antarwarga kelas, berbuat terbaik dan saling memberi dukungan, suasana gembira, tertib tanpa paksaan, komunikasi terbuka dan dialogis, dan ada rasa kebersamaan.

c. nilai-nilai yang akan dikembangkan merupakan hasil dari diskusi antara pihak sekolah, orangtua, dan tokoh masyarakat.

d. keempat strategi pendidikan nilai -inkulkasi, pemodelan, fasilitasi, dan pengembangan ketrampilan- dilakukan secara simultan dengan penekanan silih berganti tergantung konteksnya. 
Mengingat sekolah memiliki sumberdaya manusia yang relatif memadai dan memiliki otoritas legal-formal sebagai pusat pendidikan, maka inisiatif pengembangan program pendidikan nilai secara formal biasanya datang dari sekolah. Namun demikian tidak berarti bahwa orangtua dan tokoh masyarakat tidak berhak memiliki inisiatif untuk program ini. Ide bisa datang dari manapun tetapi koordinator dan penanggung jawab secara formal sebaiknya sekolah.

\section{E. Contoh Program: Usaha Preventif Penyalahgunaan Narkoba Sebagai Pengembangan Program Pendidikan Nilai Komprehensif}

Nama Kegiatan: Usaha Preventif Penyalahgunaan Narkoba.

Waktu Pelaksanaan: Setiap saat, sepanjang waktu, terus-menerus.

Tempat Pelaksanaan: Di sekolah, masyarakat dan rumah.

Pelaksana Program: guru, orangtua, nara sumber (mantan pengguna narkoba, aktivis gerakan pemberantasan narkoba, misalnya GRANAT, GERAM, POLISI).

\section{Strategi Pelaksanaan Program}

Strategi pelaksanaan program ini dilakukan secara bertahap, mulai dari inisiasi sampai tindak lanjut kegiatan dalam rangka menjaga kesinambungan program. Untuk mengawali program ini, guru harus mampu meyakinkan semua pihak, termasuk para siswa dan orangtua mereka bahwa masalah penyalahgunaan narkoba sudah sedemikian mengkhawatirkan sehingga upaya pencegahan dan penaggulangan perlu dilakukan sesegera mungkin dengan melibatkan seluruh elemen masyarakat secara sinergis. Untuk itu, dengan mengundang aktivis gerakan pemberantasan narkoba dan mantan pengguna narkoba, diharapkan para siswa memiliki gambaran yang memadai 
tentang kondisi mereka yang terancam oleh upaya-upaya para pengedar narkoba dengan segala strategi dan tipu daya mereka untuk mencari mangsa baru.

\section{Inkulkasi}

Pada tahap awal ini, kegiatan lebih ditekankan pada inkulkasi nilai dan moral berkaitan dengan penyalahgunaan narkoba. Ada semacam target nilai yang ingin dikembangkan (target values) di antara pihak sekolah, keluarga, dan masyarakat, misalnya menghargai orang lain dan diri sendiri, dedikasi, tanggung-jawab, patriotisme, keberanian, dsb. Dengan mendengarkan kisah atau melihat tayangan video-audio visual, siswa, termasuk orangtua dan guru serta para staf menyadari pentingnya nilai-nilai inti yang harus mereka kembangkan untuk sebagi usaha preventif penyalahgunaan narkoba.

\section{Pemodelan}

Sosok mantan pecandu narkoba yang telah sadar (kembali ke jalan yang benar). Sosok aktivis pemberantasan narkoba yang gigih.

Kehadiran mantan pecandu narkoba dan aktivis pemberantasan narkoba dapat menjadi model bagi siswa, termasuk orangtua dan guru serta siapa pun yang peduli dengan masalah penyalahgunaan narkoba. Dengan strategi berbagi: pengalaman, perasaan dan keyakinan, ketrampilan, kepentingan dan kepedulian, upaya untuk mencari model yang tepat dalam rangka pencegahan penyalahgunaan narkoba dapat dilakukan.

\section{Fasilitasi}


Berbagai kegiatan dapat dilakukan sebagai strategi fasilitasi nilai dan moral yang diperlukan dalam rangka pencegahan penyalahgunaan narkoba. Dengan mendatangkan sosok mantan pecandu narkoba dan aktivis pemberantasan narkoba, usaha fasilitasi dapat dilakukan misalnya dalam bentuk wawancara, menentukan pendapat, evalusi diri, simulasi, konsultasi teman sebaya, diskusi dilema moral dan pertanyaan untuk memperjelas nilai. Debat, pembuatan aturan kelas, menulis surat pembaca, dan sebgainya dapat dilakukan sebagai tindak lanjut dari pertemuan ini. Kesemuanya ini adalah dalam rangka memfasilitasi siswa agar tertanam nilai-nilai yang diperlukan untuk menanggulangi penyalahgunaan narkoba.

\section{Pengembangan Ketrampilan Nilai dan Moral}

Resolusi Konflik, berpikir kritis, tahan terhadap tekanan teman sebaya

Model ini diarahkan agar siswa (termasuk orangtua dan guru) memiliki ketrampilan untuk menyelesaikan konflik. Konflik yang diketengahkan misalnya antara ajakan teman sebaya untuk mengkonsumsi narkoba dengan masa depan dirinya yang cerah. Melalui cara ini siswa dihadapkan pada konflik pilihan yang memerlukan ketrampilan untuk mengatasinya. Siswa diberi tugas bagaimana solusi untuk menyelesaikan konflik tersebut. Solusi yang dipilih oleh siswa diberi berbagai argumen yang menguatkan bahwa solusi tersebut merupakan solusi terbaik yang dipilih siswa. Tidak kalah pentingnya dalam rangka pengembangan ketrampilan ini adalah ketrampilan sosial, pengetahuan dan ketrampilan akademik, dan kerjasama.

\section{F. Penutup}


Mengingat semakin kompleks dan berat masalah sosial yang kita hadapi saat ini dan di masa mendatang, maka peran sekolah sebagai agen pelestari nilai-nilai dan ketrampilan sosial yang utama, di samping keluarga dan masyarakat, harus diterjemahkan secara jelas dan diwujudkan dalam implementasi pendidikan dan pembelajaran yang bersifat komptehensif dan memadai. Pengetahuan, nilai, sikap, dan ketrampilan berkaitan dengan permasalah sosial harus diberikan kepada para siswa secara simultan. Pembelajaran yang bersifat kontekstual dan konstruktivistik nampaknya mendapatkan tempat yang sentral dalam usaha pendidikan dewasa ini. Dengan demikian, siswa tidak akan gagap ketika harus menghadapi berbagai masalah sosial dalam kehidupan mereka karena telah memiliki bekal pengetahuan, sikap, nilai, dan ketrampilan yang memadai.

Sekalipun seorang guru telah melakukan kegiatan terbaik dengan menggabungkan strategi melalui penyanpaian informasi, inklukasi, fasilitasi, pemodelan, dan pengembangan ketrampilan berkaitan dengan nilai dan moral di dalam kelas akan ada siswa yang (1) menerima nilai-nilai yang guru ajarkan dan akan bertindak secara konsisten dengan nilai-nilai itu; (2) menerima nilai-nilai yang guru ajarkan tetapi tidak akan bertindak secara konsisten dengan nilai-nilai itu; (3) hampir menerima nilai-nilai yang guru ajarkan tetapi belum mantap; dan (4) menolak atau mengabaikan atau tidak setuju atau lebih banyak tidak setujunya dibanding yang ia setujui dengan anda. Untuk itu, guru tidak boleh putus asa dalam menghadapinya. Dalam pendidikan nilai yang komprehensif memangdibutuhkan ketekunan dan kerja keras dari semua pihak tekait. 


\section{Daftar pustaka}

Albert, L. (1989). A Teacher's guide to cooperative discipline. USA: AGS.

Brinkerhoff, D.B. \& White, L.K. (1988). Essentials of sociology. New York: West Publishing Company.

Chapin, J.R. \& Messick, R.G. ( 1992). Elementary social studies a practical guide second edition. Ney York: Longman.

Goode, E. (1984). Deviant behavior second edition. New Jersey: Prentice-Hall.

Hill, B. V. (1991). Values education in australian schools. Victoria: ACER

Kirschenbaum, H. (1995). 100 ways to enhance values and morality in schools and youth settings. Boston: Allyn and Bacon.

McDowell, M.(1986). Social problems. New York: Macmillan Publishing Company.

Martorella, P.H., (1994). Social studies for elementary school children, developing young citizen. New York: Macmillan College Publishing Company.

\section{Biodata penulis}

Suyato, lahir di Wonogiri, 16 juni 1967, menyelesaikan S1 PMP dan KN IKIP Yogyakarta tahun 1993. Menjadi dosen pada jurusan yang sama sejak 1994. Kini tengah menyelesakan revisi Tesis pada Program Pendidikan Ilmu Pengetahuan Sosial Program Pascasarjana UNY. 